Article

\title{
Exploring Orthogonality between Halogen and Hydrogen Bonding Involving Benzene
}

\author{
Alessandra Forni ${ }^{1, *(\mathbb{D})}$, Rosario Russo ${ }^{2}$, Giacomo Rapeti ${ }^{2}$, Stefano Pieraccini ${ }^{1,2, *(D)}$ and Maurizio Sironi ${ }^{1,2, *}$ (D) \\ 1 Istituto di Scienze e Tecnologie Chimiche "Giulio Natta"—CNR, INSTM RU, Via Golgi 19, 20133 Milan, Italy \\ 2 Department of Chemistry, Università degli Studi di Milano, INSTM RU, Via Golgi 19, 20133 Milano, Italy; \\ russorosario@itis-molinari.eu (R.R.); giacomo.rapeti@studenti.unimi.it (G.R.) \\ * Correspondence: alessandra.forni@scitec.cnr.it (A.F.); stefano.pieraccini@unimi.it (S.P.); \\ maurizio.sironi@unimi.it (M.S.)
}

check for updates

Citation: Forni, A.; Russo, R.; Rapeti, G.; Pieraccini, S.; Sironi, M. Exploring Orthogonality between Halogen and Hydrogen Bonding Involving

Benzene. Molecules 2021, 26, 7126.

https://doi.org/10.3390/

molecules26237126

Academic Editors: Carlo Gatti, David

L. Cooper, Miroslav Kohout and

Maxim L. Kuznetsov

Received: 18 October 2021

Accepted: 23 November 2021

Published: 25 November 2021

Publisher's Note: MDPI stays neutral with regard to jurisdictional claims in published maps and institutional affiliations.

Copyright: (c) 2021 by the authors. Licensee MDPI, Basel, Switzerland. This article is an open access article distributed under the terms and conditions of the Creative Commons Attribution (CC BY) license (https:// creativecommons.org/licenses/by/ $4.0 /)$.

\begin{abstract}
The concept of orthogonality between halogen and hydrogen bonding, brought out by Ho and coworkers some years ago, has become a widely accepted idea within the chemists' community. While the original work was based on a common carbonyl oxygen as acceptor for both interactions, we explore here, by means of M06-2X, M11, $\omega$ B97X, and $\omega$ B97XD/aug-cc-PVTZ DFT calculations, the interdependence of halogen and hydrogen bonding with a shared $\pi$-electron system of benzene. The donor groups (specifically $\mathrm{NCBr}$ and $\mathrm{H}_{2} \mathrm{O}$ ) were placed on either or the same side of the ring, according to a double T-shaped or a perpendicular geometry, respectively. The results demonstrate that the two interactions with benzene are not strictly independent on each other, therefore outlining that the orthogonality between halogen and hydrogen bonding, intended as energetical independence between the two interactions, should be carefully evaluated according to the specific acceptor group.
\end{abstract}

Keywords: halogen bonding; hydrogen bonding; orthogonal interactions; DFT calculations; halogen- $\pi$ interaction

\section{Introduction}

Halogen bonding $(\mathrm{XB})$, a noncovalent interaction where the halogen atom acts as electrophilic species [1], is nowadays a well-recognized molecular interaction with applications in biochemistry [2-11] and materials science [12,13], including non-linear optics [14-16] and liquid crystals [17-19]. This interaction, schematized as $\mathrm{R}-\mathrm{X} \cdots \mathrm{B}(\mathrm{X}=\mathrm{Cl}, \mathrm{Br}$, or $\mathrm{I}$; $\mathrm{B}=\mathrm{Lewis}$ base; $R$ = substituent), has been explained by the existence of a region of positive electrostatic potential, named $\sigma$-hole, on the outermost surface of the covalently-bonded halogen atom and narrowly confined on the elongation of the $\mathrm{R}-\mathrm{X}$ covalent bond axis [20]. Its presence has been recently demonstrated through valence bond spin-coupled calculations [21], allowing to get a rigorous ab initio validation of the qualitative models previously proposed [20]. The key role of the $\sigma$-hole in activating XB has been particularly emphasized by molecular mechanics/molecular dynamics simulations of halogen-bonded ligand-protein systems. In fact, such calculations were able to reproduce the experimentally observed structural features only if the charge anisotropy around the halogen atom was correctly described through introduction of a positively charged particle mimicking the $\sigma$-hole [22-27]. The presence of the $\sigma$-hole has also been demonstrated by experimental charge density studies [28-35].

Analysis of crystal structures of halogenated molecules has revealed that $\mathrm{XB}$ often acts in a cooperative way with hydrogen bonding (HX) [36-39]. In particular, Ho and coworkers reported that halogen and hydrogen bonds can be geometrically perpendicular to and energetically independent on each other, when the involved $\mathrm{X}$ and $\mathrm{H}$ donor atoms interact with the same carbonyl group in protein-ligand complexes [40]. The authors then proposed the concept of $\mathrm{XB} / \mathrm{HB}$ orthogonality, paving the way for the development of new strategies aimed at the rational design of halogenated ligands as drugs [36]. 
Prompted by the conclusions obtained by Ho and coworkers on the $\mathrm{CO} \cdots \mathrm{X} / \mathrm{H}$ orthogonality [40], we have considered the possibility to extend this concept to the case where the halogen and hydrogen donor atoms share a common benzene $\pi$-electron system as bonding acceptor. In previous studies [41-43], we extensively investigated from a theoretical point of view the $\mathrm{XB}$ established between a series of halogenated molecules ( $\mathrm{NCX}$ or $\mathrm{PhX}$ where $\mathrm{X}=\mathrm{F}, \mathrm{Cl}, \mathrm{Br}, \mathrm{I}$ ) and the aromatic system of benzene in the T-shaped configuration, an interaction rather ubiquitous in biological systems [44,45]. Here, the more appropriated computational protocols proposed in our previous studies are used to investigate the simultaneous interaction of $\mathrm{NCBr}$ and $\mathrm{H}_{2} \mathrm{O}$, two relatively strong $\mathrm{XB}$ and $\mathrm{HB}$ donors, respectively, with a common $\pi$-electron system of benzene. To this purpose, two geometrical approaches have been examined, that is, a 'double T-shaped' one, where $\mathrm{NCBr}$ and $\mathrm{H}_{2} \mathrm{O}$, both in T-shaped configuration with respect to benzene, point to the ring from opposite sides; and a 'perpendicular' approach, where $\mathrm{NCBr}$ and $\mathrm{H}_{2} \mathrm{O}$ lie on the same side of the ring forming a right angle with the center of the ring. Of course, the concept of orthogonality we want here to explore refers uniquely to the energetical independence of the two interactions rather than to the geometrical arrangement of the interacting species, which strictly applies only to the 'perpendicular' approach. To provide solid support to our conclusions, different functionals have been used for this analysis, that is M06-2X, M11, and $\omega \mathrm{B} 97 \mathrm{X}$, chosen among the better performing on the basis of our previous investigation on the NCX $\cdots \pi \mathrm{XB}$ [42]. Owing to the demonstrated importance of the dispersion forces, besides the electrostatic ones, in describing the RX $\cdots \pi$ interaction [42], additional calculations were performed with a DFT-D functional, $\omega$ B97XD, which explicitly includes a posteriori dispersion correction.

\section{Results}

\subsection{Double T-Shaped Configuration}

The simultaneous formation of $\mathrm{XB}$ and $\mathrm{HB}$ with benzene, where the respective donors are located on opposite sides with respect to the plane of the ring, represents a quite common motif in organic crystal structures, as denoted by a survey of the Cambridge Structural Database (CSD version 5.42, February 2021) [46]. Up to 962 hits were in fact obtained by searching for organic compounds containing $\mathrm{A}-\mathrm{X} \cdots \mathrm{c}(\mathrm{Ph}) \cdots \mathrm{H}-\mathrm{B}$ fragments (being $\mathrm{A}$ and $\mathrm{B}$ generic atoms, $\mathrm{C}(\mathrm{Ph})$ the geometrical centroid of a phenyl ring, and $\mathrm{X}=\mathrm{Cl}, \mathrm{Br}$ or I) with $\mathrm{X} \cdots \mathrm{c}(\mathrm{Ph})$ and $\mathrm{c}(\mathrm{Ph}) \cdots \mathrm{H}$ distances in the $3.0-4.0 \AA$ and $2.0-3.0 \AA$ range, respectively, and both $\mathrm{A}-\mathrm{X} \cdots \mathrm{c}(\mathrm{Ph})$ and $\mathrm{X} \cdots \mathrm{c}(\mathrm{Ph}) \cdots \mathrm{H}$ angles in the $150^{\circ}-180^{\circ}$ range.

A first set of calculations were performed on dimers of $\mathrm{NCBr}$ or $\mathrm{H}_{2} \mathrm{O}$ with benzene (or $\mathrm{bz}$ ) in T-shaped configuration (see structure (a) in Figures 1 and 2, respectively), with the $\mathrm{Br}$ or the $\mathrm{H}$ atom, respectively, approaching the center of the ring. The binding energy curves, computed at the M06-2X/aug-cc-PVTZ level of theory, are plotted in Figures 1 and 2 (see Figures S1-S6 for the M11, $\omega$ B97X, and $\omega$ B97XD binding energy curves and Tables S1-S8 for the $\Delta \mathrm{E}$ vs. $\mathrm{r}$ numerical values). Comparing halogen and hydrogen bonds, the four examined functionals display the same trend in the values of equilibrium distances, $r_{\text {eq, }}$ and interaction energies, $\Delta \mathrm{E}_{\mathrm{XB}}$ and $\Delta \mathrm{E}_{\mathrm{HB}}$ for $\mathrm{XB}$ and $\mathrm{HB}$, respectively (see Table 1). For both the $\mathrm{NCBr} \cdot \mathrm{bz}$ and $\mathrm{H}_{2} \mathrm{O} \cdot \mathrm{bz}$ optimized dimers, in fact, $\mathrm{M} 06-2 \mathrm{X}$ provides the higher $\Delta \mathrm{E}_{\mathrm{XB}}$ and $\triangle \mathrm{E}_{\mathrm{HB}}$ interaction energies, respectively, which correspond to the shorter intermolecular distances. The M11 functional gives the lower interaction energies, with differences in $\Delta \mathrm{E}_{\mathrm{XB}}$ and $\Delta \mathrm{E}_{\mathrm{HB}}$ amounting to 0.35 and $0.42 \mathrm{kcal} / \mathrm{mol}$ (i.e., 9.1 and $12.2 \%$ ), respectively, compared to the M06-2X values. Finally, the $\omega$ B97X and $\omega$ B97XD functionals provide the longer equilibrium distances and energy values intermediate between the M06-2X and the M11 ones. Comparing the two related $\omega$ B97X and $\omega$ B97XD hybrid functionals, it is found that the empirical dispersion correction does not provide any significant variation in both equilibrium distances and energies. Interestingly, however, while equilibrium distances of both interactions are slightly elongated when explicitly including dispersion, the corresponding energies undergo different, though very small, variations according to the $\mathrm{HB}$ or $\mathrm{XB}$ interaction. In the first case, in fact, $\triangle \mathrm{E}$ increases in magnitude, as generally 
obtained going from DFT to DFT-D calculations on non-covalently bound systems [47,48], while for the $\mathrm{XB}$ interaction the opposite trend is observed, suggesting that dispersion effects are somehow taken into account in the $\omega$ B97X functional, too.

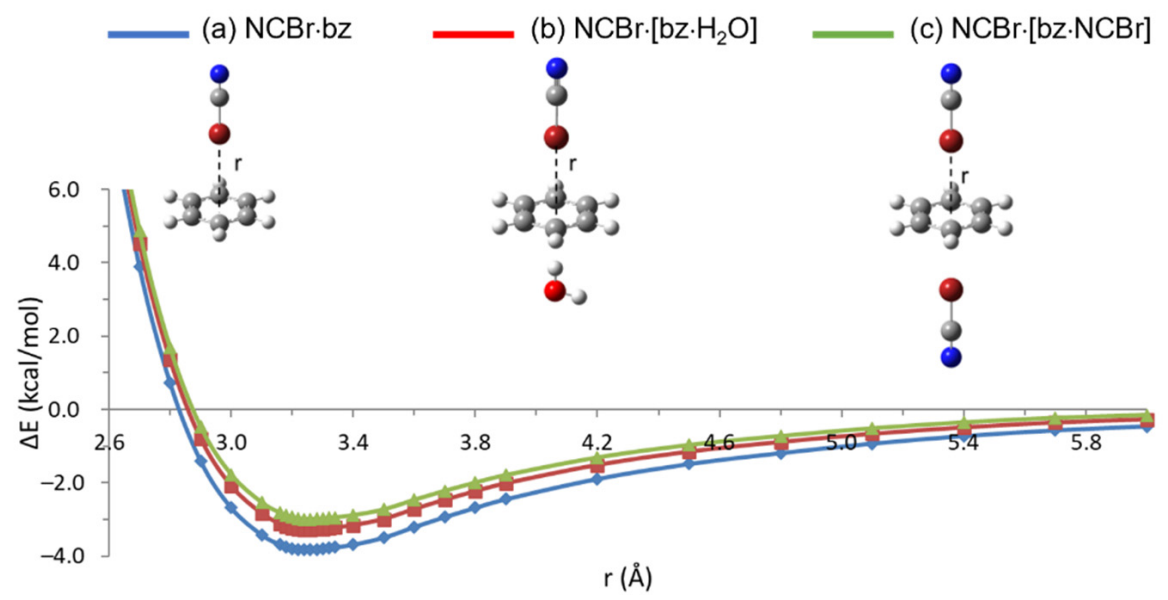

Figure 1. Binding energy curves, $\Delta \mathrm{E}$, vs. $\mathrm{Br}$ distance from the center of benzene ring, $\mathrm{r}$, computed for (a) $\mathrm{NCBr} \cdot \mathrm{bz}$ (blue line), (b) NCBr$\cdot\left[\mathrm{bz} \cdot \mathrm{H}_{2} \mathrm{O}\right]$ (red line) and (c) $\mathrm{NCBr} \cdot[\mathrm{bz} \cdot \mathrm{NCBr}]$ (green line) systems in the T-shaped approach at the M06-2X/aug-cc-PVTZ level of theory.

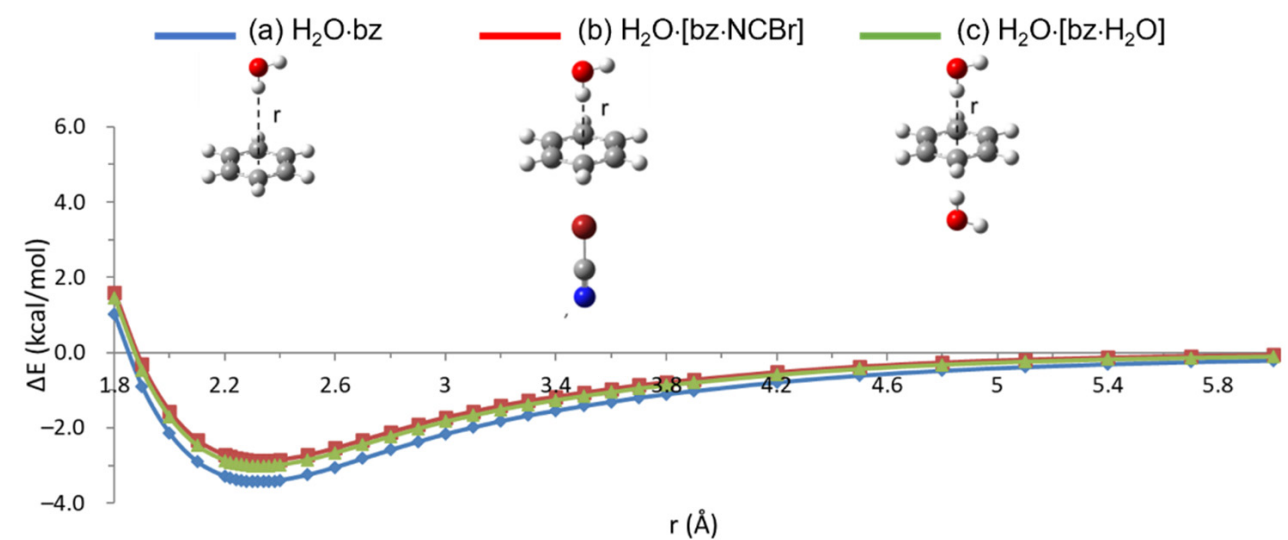

Figure 2. Binding energy curves, $\triangle \mathrm{E}$, vs. $(\mathrm{HO}) \mathrm{H}$ distance from the center of benzene ring, $\mathrm{r}$, computed for (a) $\mathrm{H}_{2} \mathrm{O} \cdot \mathrm{bz}$ (blue line), (b) $\mathrm{H}_{2} \mathrm{O} \cdot[\mathrm{bz} \cdot \mathrm{NCBr}]$ (red line) and (c) $\mathrm{H}_{2} \mathrm{O} \cdot\left[\mathrm{bz} \cdot \mathrm{H}_{2} \mathrm{O}\right]$ (green line) systems in the T-shaped approach at the M06-2X/aug-cc-PVTZ level of theory.

Table 1. Equilibrium distances $\mathrm{r}_{\mathrm{eq}}(\AA)$ and interaction energies $\Delta \mathrm{E}_{\mathrm{XB}}$ and $\Delta \mathrm{E}_{\mathrm{HB}}(\mathrm{kcal} / \mathrm{mol})$ for dimers and trimers in T-shaped and double T-shaped configurations, respectively.

\begin{tabular}{|c|c|c|c|c|c|c|}
\hline \multirow{2}{*}{ Functional } & \multicolumn{2}{|c|}{$\mathrm{NCBr} \cdot \mathrm{bz}$} & \multicolumn{2}{|c|}{$\mathrm{NCBr} \cdot\left[\mathrm{bz} \cdot \mathrm{H}_{2} \mathrm{O}\right]$} & \multicolumn{2}{|c|}{$\mathrm{NCBr} \cdot[\mathrm{bz} \cdot \mathrm{NCBr}]$} \\
\hline & $\mathbf{r}_{\mathrm{eq}}$ & $\Delta \mathrm{E}_{\mathrm{XB}}$ & $\mathrm{r}_{\mathrm{eq}}$ & $\Delta \mathrm{E}_{\mathrm{XB}}$ & $\mathrm{r}_{\mathrm{eq}}$ & $\Delta \mathrm{E}_{\mathrm{XB}}$ \\
\hline M06-2X & 3.24 & -3.83 & 3.26 & $-3.28(0.55)^{a}$ & 3.26 & $-2.99(0.84)^{a}$ \\
\hline M11 & 3.32 & -3.48 & 3.34 & $-2.90(0.58)^{a}$ & 3.34 & $-2.62(0.86)^{a}$ \\
\hline$\omega \mathrm{B} 97 \mathrm{X}$ & 3.40 & -3.67 & 3.42 & $-3.17(0.50)^{a}$ & 3.42 & $-2.92(0.75)^{\mathrm{a}}$ \\
\hline \multirow[t]{3}{*}{$\omega \mathrm{B} 97 \mathrm{XD}$} & 3.46 & -3.60 & 3.48 & $-3.14(0.46)^{a}$ & 3.48 & $-2.92(0.68)^{a}$ \\
\hline & \multicolumn{2}{|c|}{$\mathrm{H}_{2} \mathrm{O} \cdot \mathbf{b z}$} & \multicolumn{2}{|c|}{$\mathrm{H}_{2} \mathrm{O} \cdot[\mathrm{bz} \cdot \mathrm{NCBr}]$} & \multicolumn{2}{|c|}{$\mathrm{H}_{2} \mathrm{O} \cdot\left[\mathrm{bz} \cdot \mathrm{H}_{2} \mathrm{O}\right]$} \\
\hline & $\mathbf{r}_{\mathrm{eq}}$ & $\Delta \mathbf{E}_{\mathrm{HB}}$ & $\mathrm{r}_{\mathrm{eq}}$ & $\Delta \mathbf{E}_{\mathbf{H B}}$ & $\mathrm{r}_{\mathrm{eq}}$ & $\Delta \mathbf{E}_{\mathrm{HB}}$ \\
\hline M06-2X & 2.32 & -3.43 & 2.34 & $-2.88(0.55)^{b}$ & 2.34 & $-3.02(0.41)^{b}$ \\
\hline M11 & 2.34 & -3.01 & 2.34 & $-2.43(0.58)^{b}$ & 2.34 & $-2.57(0.44)^{b}$ \\
\hline$\omega \mathrm{B} 97 \mathrm{X}$ & 2.42 & -3.14 & 2.42 & $-2.64(0.50)^{b}$ & 2.42 & $-2.76(0.38)^{b}$ \\
\hline$\omega \mathrm{B} 97 \mathrm{XD}$ & 2.46 & -3.19 & 2.46 & $-2.73(0.46)^{b}$ & 2.46 & $-2.84(0.35)^{b}$ \\
\hline
\end{tabular}

${ }^{a}$ In parentheses, the increase with respect to the $\mathrm{NCBr} \cdot \mathrm{bz} \Delta \mathrm{E}_{\mathrm{XB}}$ value. ${ }^{\mathrm{b}}$ In parentheses, the increase with respect to the $\mathrm{H}_{2} \mathrm{O} \cdot \mathrm{bz} \Delta \mathrm{E}_{\mathrm{HB}}$ value. 
Finally, it should be noted that the considered T-shaped approach represents a constrained path enabling to uniquely fix the dimers' geometry for subsequent calculations on trimers. As previously reported for RX $\cdots \pi \mathrm{XB}$ systems [41], unconstrained geometry optimization of such dimers leads to a breakdown of the T-shaped geometry of the monomers, the RX molecule being slightly out from the perpendicularity with respect to the benzene plane and pointing towards a $\mathrm{CC}$ benzene bond rather than to the center of the ring. However, geometry optimization of the $\mathrm{NCBr} \cdot \mathrm{bz}$ and $\mathrm{H}_{2} \mathrm{O} \cdot \mathrm{bz}$ dimers here examined, performed at the $\omega \mathrm{B} 97 \mathrm{XD} /$ aug-cc-PVTZ level of theory, results in absolute minima, confirmed by frequency calculations, which are only 0.20 and $0.50 \mathrm{kcal} / \mathrm{mol}$ (for $\mathrm{XB}$ and $\mathrm{HB}$, respectively) more stable than the constrained T-shaped configuration (see the minimum energy geometries in Figure S7). This denotes a rather flat potential energy surface for the $\mathrm{NCBr} \cdot \mathrm{bz}$ and $\mathrm{H}_{2} \mathrm{O} \cdot \mathrm{bz}$ interacting systems, indicating that the chosen $\mathrm{T}$-shaped configuration does not represent in any way a too strong assumption affecting the subsequent results.

Keeping the optimized dimers fixed in their respective T-shaped energy minima, we then computed the binding energy curves corresponding to the T-shaped approach of either $\mathrm{NCBr}$ to bz $\cdot \mathrm{H}_{2} \mathrm{O}$ or $\mathrm{H}_{2} \mathrm{O}$ to bz$\cdot \mathrm{NCBr}$ from the opposite site with respect to $\mathrm{NCBr}$ or $\mathrm{H}_{2} \mathrm{O}$, respectively, according to a 'double T-shaped' geometry (see structure (b) in Figures 1 and 2, respectively). The binding energies of the formed $\mathrm{NCBr} \cdot\left[\mathrm{bz} \cdot \mathrm{H}_{2} \mathrm{O}\right]$ and $\mathrm{H}_{2} \mathrm{O} \cdot[\mathrm{bz} \cdot \mathrm{NCBr}]$ trimers have been computed as the difference between the total energy and the sum of the contributions deriving from the incoming molecule and that of the fixed hydrogenor halogen-bonded complex. Of course, such two-step formation of the trimer does not reproduce the real situation, where $\mathrm{XB}$ and $\mathrm{HB}$ are expected to be concomitantly established during the aggregation process, but it allows to separately evaluate the contributions of the two interactions.

Comparison between the $\Delta \mathrm{E}_{\mathrm{XB}}$ values obtained for the NCBr.bz dimer and those determined for the $\mathrm{NCBr} \cdot\left[\mathrm{bz} \cdot \mathrm{H}_{2} \mathrm{O}\right]$ trimer should provide an indication about the orthogonality between the two interactions: if no significant $\triangle \mathrm{E}_{\mathrm{XB}}$ variations are observed, $\mathrm{XB}$ and $\mathrm{HB}$ can be considered orthogonal. As a countercheck, the results obtained for $\mathrm{H}_{2} \mathrm{O} \cdot \mathrm{bz}$ and $\mathrm{H}_{2} \mathrm{O} \cdot[\mathrm{bz} \cdot \mathrm{NCBr}]$ should lead to comparable conclusions.

The results are collected in Table 1 and the binding energy curves obtained by M06-2X calculations are plotted in Figures 1 and 2 (see Figures S1-S6 for the M11, $\omega$ B97X, and $\omega \mathrm{B} 97 \mathrm{XD}$ binding energy curves and Tables $\mathrm{S} 1-\mathrm{S} 8$ for the $\Delta \mathrm{E}$ vs. $\mathrm{r}$ numerical values). It is found that the minimum energy geometry of $\mathrm{XB}$ is only slightly perturbed when $\mathrm{NCBr}$ interacts with $\left[\mathrm{bz} \cdot \mathrm{H}_{2} \mathrm{O}\right]$ rather than with $\mathrm{bz}$ alone, with elongations lying within the step size used to build up the curves ( $0.02 \AA$ in the minimum energy region). Even lower elongations are obtained for HB. Considering the interaction energies, however, non-negligible variations are obtained comparing the same interaction in the dimer and in the trimer. For example, looking at the results obtained with the M11 functional, providing the larger variations, $\Delta \mathrm{E}_{\mathrm{XB}}$ decreases in absolute value from -3.48 to $-2.90 \mathrm{kcal} / \mathrm{mol}$ and $\Delta \mathrm{E}_{\mathrm{HB}}$ from -3.01 to -2.43 , with a comparable percentage reduction of $16.7\left(\Delta \mathrm{E}_{\mathrm{XB}}\right)$ and $19.3 \%\left(\Delta \mathrm{E}_{\mathrm{HB}}\right)$. These results are confirmed by M06-2X, $\omega \mathrm{B} 97 \mathrm{X}$, and $\omega \mathrm{B} 97 \mathrm{XD}$ calculations, providing percentage reductions of $14.4\left(\Delta \mathrm{E}_{\mathrm{XB}}\right), 16.0 \%\left(\Delta \mathrm{E}_{\mathrm{HB}}\right) ; 13.6\left(\Delta \mathrm{E}_{\mathrm{XB}}\right), 15.9 \%\left(\Delta \mathrm{E}_{\mathrm{HB}}\right)$; and $12.8\left(\Delta \mathrm{E}_{\mathrm{XB}}\right), 14.4 \%\left(\Delta \mathrm{E}_{\mathrm{HB}}\right)$, respectively. The destabilization associated with the trimer formation indicates a strong perturbation of the whole $\pi$-electron system of benzene within the dimer, allowing to conclude that $\mathrm{XB}$ and $\mathrm{HB}$ on either side of benzene are not strictly orthogonal interactions.

The slightly greater destabilization of $\mathrm{HB}$ with respect to $\mathrm{XB}$ in the presence of the other perturbing interaction on the other side of benzene should be imputed to the here considered NCBr.bz XB, which is slightly stronger (by $0.40,0.47,0.53$, or $0.41 \mathrm{kcal} / \mathrm{mol}$ according to the M06-2X, M11, $\omega$ B97X, or $\omega$ B97XD functional) than the $\mathrm{H}_{2} \mathrm{O} \cdot \mathrm{bz} \mathrm{HB}$. This observation is supported by additional calculations on 'purely' halogen-bonded or hydrogen-bonded trimers, where the same molecule approaches the benzene ring from either side, resulting in double T-shaped $\mathrm{NCBr} \cdot[\mathrm{bz} \cdot \mathrm{NCBr}]$ or $\mathrm{H}_{2} \mathrm{O} \cdot\left[\mathrm{bz} \cdot \mathrm{H}_{2} \mathrm{O}\right]$ systems (see structure (c) in 
Figures 1 and 2, respectively). A quite different behavior is observed for the halogenbonded and the hydrogen-bonded trimers (see Table 1, Figures 1, 2 and S1-S6 for the M06-2X, M11, $\omega$ B97X, and $\omega$ B97XD binding energy curves, respectively, and Tables S1-S8 for the $\Delta \mathrm{E}$ vs. $\mathrm{r}$ numerical values). In fact, looking again at the M11 results, calculations provide a much stronger reduction of the $\mathrm{XB}$ interaction energy with respect to that computed for the $\mathrm{HB}$ one, with percentage reductions equal to $24.7\left(\Delta \mathrm{E}_{\mathrm{XB}}\right)$ and $14.6 \%\left(\Delta \mathrm{E}_{\mathrm{HB}}\right)$. Similarly, M06-2X, $\omega \mathrm{B} 97 \mathrm{X}$, and $\omega \mathrm{B} 97 \mathrm{XD}$ calculations provide percentage reductions of $21.9\left(\Delta \mathrm{E}_{\mathrm{XB}}\right), 12.0 \%\left(\Delta \mathrm{E}_{\mathrm{HB}}\right) ; 20.4\left(\Delta \mathrm{E}_{\mathrm{XB}}\right), 12.1 \%\left(\Delta \mathrm{E}_{\mathrm{HB}}\right) ; 18.9\left(\Delta \mathrm{E}_{\mathrm{XB}}\right), 11.0 \%\left(\Delta \mathrm{E}_{\mathrm{HB}}\right)$, respectively. Such results can be explained by considering that the $\pi$-electron system of benzene is perturbed in a greater extent by the stronger $\mathrm{NCBr} \cdot \mathrm{bz} \mathrm{XB}$ with respect to the weaker $\mathrm{H}_{2} \mathrm{O} \cdot \mathrm{bz} \mathrm{HB}$.

\subsection{Perpendicular Configuration}

To explore the configuration where both $\mathrm{NCBr}$ and $\mathrm{H}_{2} \mathrm{O}$ molecules lie on the same side of the benzene ring, perpendicular to each other, preliminary M06-2X/aug-cc-PVTZ calculations have been performed on the halogen- and hydrogen-bonded dimers with benzene, aimed at establishing the constrained path of minimum energy towards the center of the ring. Binding energy curves were calculated by moving either $\mathrm{NCBr}$ or the interacting $\mathrm{OH}$ group along the line through the center of the ring and forming a $45^{\circ}$ angle with the benzene plane. Both approaches where the projection of the line on this plane crosses one carbon atom or the center of a CC bond (see Figures S8 and S9, respectively) have been examined. Moreover, in the case of the hydrogen-bonded dimer, the non-interacting hydrogen atom was directed either inward or outward with respect to the benzene ring. As shown in Table S9, the more stable approach was found to be along the center of a CC bond for both dimers, with the non-interacting $\mathrm{H}$ atom of water outwards with respect to the benzene ring (see structure (a) in Figures 3 and 4 for the $\mathrm{NCBr} \cdot \mathrm{bz}$ and $\mathrm{H}_{2} \mathrm{O} \cdot \mathrm{bz}$ dimers, respectively). Such an approach was then chosen for all the subsequent calculations.

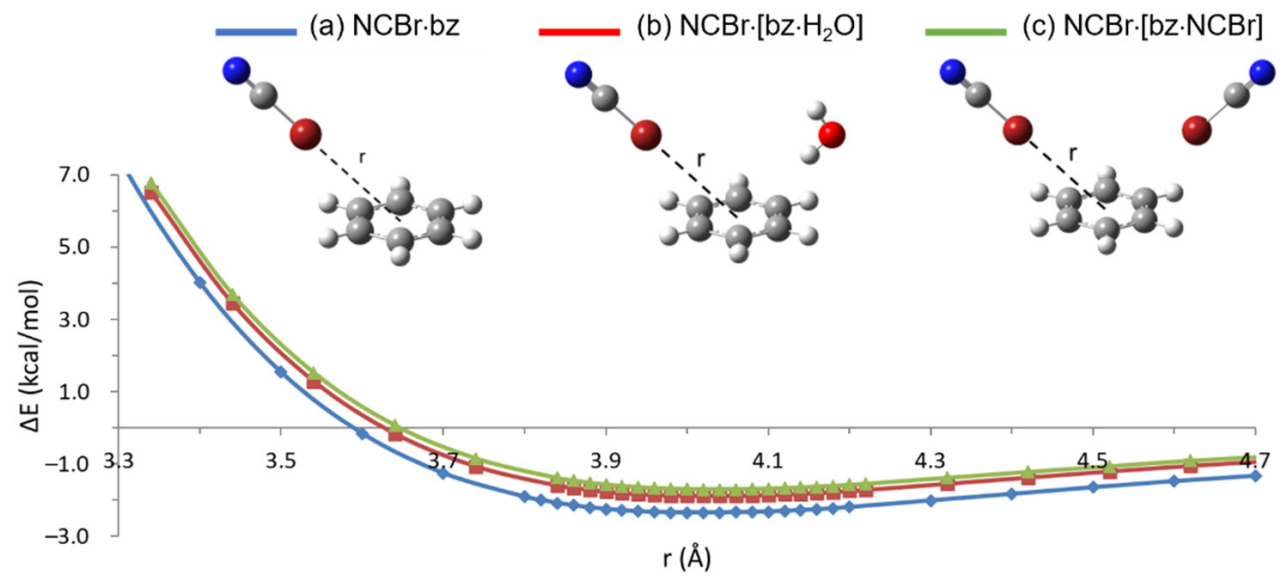

Figure 3. Binding energy curves, $\triangle \mathrm{E}$, vs. $\mathrm{Br}$ distance from the center of benzene ring, $\mathrm{r}$, computed for (a) $\mathrm{NCBr} \cdot \mathrm{bz}$ (blue line), (b) $\mathrm{NCBr} \cdot\left[\mathrm{bz} \cdot \mathrm{H}_{2} \mathrm{O}\right]$ (red line), and (c) $\mathrm{NCBr} \cdot[\mathrm{bz} \cdot \mathrm{NCBr}]$ (green line) systems in the perpendicular approach at the M06-2X/aug-cc-PVTZ level of theory.

As expected, the resulting $\Delta \mathrm{E}$ values (see Table 2, Figures 3, 4 and S10-S15 for the M06$2 \mathrm{X}, \mathrm{M} 11, \omega \mathrm{B} 97 \mathrm{X}$, and $\omega \mathrm{B} 97 \mathrm{XD}$ binding energy curves, respectively, and Tables S10-S17 for the $\Delta \mathrm{E}$ vs. $\mathrm{r}$ numerical values) are lower than those computed for the T-shaped configuration, because such a 'bent' approach is even farther, compared to the T-shaped one, from the minimum energy path (see Figure S7). However, it is interesting to note that $\mathrm{XB}$ is now slightly less stable (by $0.17,0.20,0.13$, and $0.25 \mathrm{kcal} / \mathrm{mol}$ according to the M06$2 \mathrm{X}, \mathrm{M} 11, \omega \mathrm{B} 97 \mathrm{X}$, and $\omega \mathrm{B} 97 \mathrm{XD}$ functional, respectively) than $\mathrm{HB}$, differently from what derived for the T-shaped configuration. Such a result could be explained by the greater directionality of $\mathrm{XB}$ with respect to $\mathrm{HB}$, due the more restricted positive region of the electrostatic potential on the halogen atom, compared to that hemispherically distributed 
around the hydrogen atom [49]. In the present approach, the NCBr molecule is then more affected, with respect to $\mathrm{H}_{2} \mathrm{O}$, by being quite far from the minimum energy path.

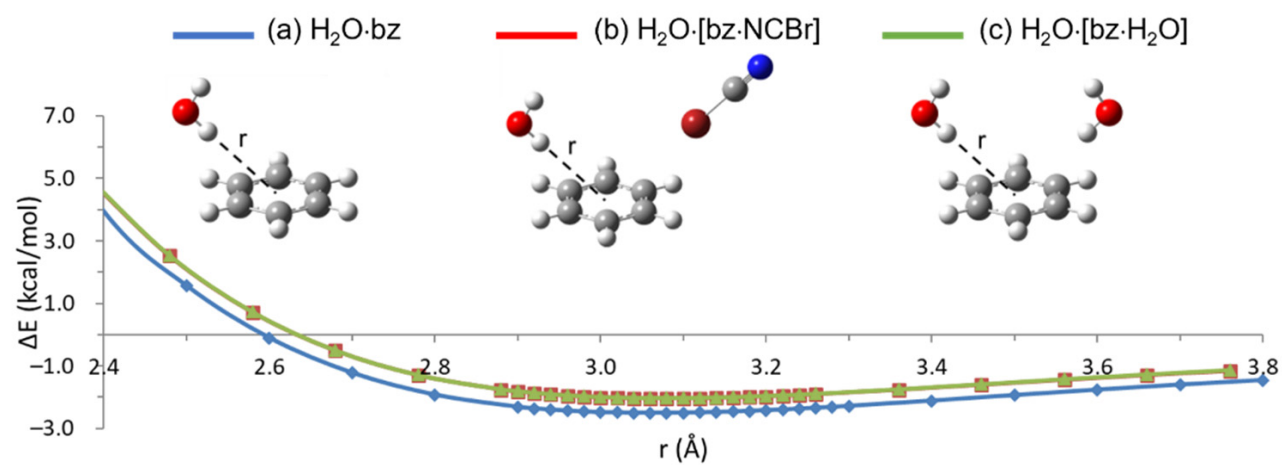

Figure 4. Binding energy curves, $\triangle \mathrm{E}$, vs. $(\mathrm{HO}) \mathrm{H}$ distance from the center of benzene ring, $r$, computed for (a) $\mathrm{H}_{2} \mathrm{O} \cdot \mathrm{bz}$ (blue line), (b) $\mathrm{H}_{2} \mathrm{O} \cdot[\mathrm{bz} \cdot \mathrm{NCBr}]$ (red line), and (c) $\mathrm{H}_{2} \mathrm{O} \cdot\left[\mathrm{bz} \cdot \mathrm{H}_{2} \mathrm{O}\right]$ (green line) systems in the perpendicular approach at the M06-2X/aug-cc-PVTZ level of theory.

Compared with the results obtained on dimers in T-shaped configuration, the higher interaction energies are obtained with the $\omega$ B97X functional, while M11 still provides the lower $\Delta \mathrm{E}$ values (see Table 2). Moreover, the examined functionals provide much more different interaction energies despite rather similar equilibrium distances. The variations from the $\omega \mathrm{B} 97 \mathrm{X}$ values to the M11 ones amount to $0.68\left(\Delta \mathrm{E}_{\mathrm{XB}}\right)$ and $0.61\left(\Delta \mathrm{E}_{\mathrm{HB}}\right) \mathrm{kcal} / \mathrm{mol}$, corresponding to 27.5 and $23.5 \%$ reductions with respect to the higher $\omega$ B97X values. Such discrepancies are much higher than those (9.1 and 12.2\%) determined for the T-shape approach. Considering that, in the two different approaches, we are dealing with the same molecules in different orientations, it may be hypothesized that the larger discrepancies observed for the bent dimers could be ascribed to the fact that this orientation is more outside, with respect to the T-shaped configuration, the minimum energy one, implying a stronger angular dependent energy bias [50].

Table 2. Equilibrium distances $\mathrm{r}_{\mathrm{eq}}(\AA)$ and interaction energies $\Delta \mathrm{E}_{\mathrm{XB}}$ and $\Delta \mathrm{E}_{\mathrm{HB}}(\mathrm{kcal} / \mathrm{mol})$ for dimers and trimers in perpendicular configuration.

\begin{tabular}{|c|c|c|c|c|c|c|}
\hline \multirow{2}{*}{ Functional } & \multicolumn{2}{|c|}{$\mathrm{NCBr} \cdot \mathrm{bz}$} & \multicolumn{2}{|c|}{$\mathrm{NCBr} \cdot\left[\mathrm{bz} \cdot \mathrm{H}_{2} \mathrm{O}\right]$} & \multicolumn{2}{|c|}{$\mathrm{NCBr} \cdot[\mathrm{bz} \cdot \mathrm{NCBr}]$} \\
\hline & $\mathbf{r}_{\mathrm{eq}}$ & $\Delta \mathrm{E}_{\mathbf{X B}}$ & $r_{e q}$ & $\Delta \mathrm{E}_{\mathbf{X B}}$ & $\mathbf{r}_{\mathrm{eq}}$ & $\Delta \mathrm{E}_{\mathbf{X B}}$ \\
\hline M06-2X & 4.02 & -2.34 & 4.02 & $-1.88(0.46)^{a}$ & 4.04 & $-1.70(0.64)^{a}$ \\
\hline M11 & 4.06 & -1.79 & 4.08 & $-1.30(0.49)^{a}$ & 4.10 & $-1.12(0.67)^{a}$ \\
\hline$\omega \mathrm{B} 97 \mathrm{X}$ & 4.09 & -2.47 & 4.11 & $-2.00(0.47)^{\mathrm{a}}$ & 4.11 & $-1.83(0.64)^{a}$ \\
\hline \multirow[t]{3}{*}{$\omega \mathrm{B} 97 \mathrm{XD}$} & 4.17 & -2.30 & 4.17 & $-1.90(0.40)^{\mathrm{a}}$ & 4.19 & $-1.77(0.53)^{a}$ \\
\hline & \multicolumn{2}{|c|}{$\mathrm{H}_{2} \mathrm{O} \cdot \mathrm{bz}$} & \multicolumn{2}{|c|}{$\mathrm{H}_{2} \mathrm{O} \cdot[\mathrm{bz} \cdot \mathrm{NCBr}]$} & \multicolumn{2}{|c|}{$\mathrm{H}_{2} \mathrm{O} \cdot\left[\mathrm{bz} \cdot \mathrm{H}_{2} \mathrm{O}\right]$} \\
\hline & $r_{\text {eq }}$ & $\Delta \mathbf{E}_{\mathrm{HB}}$ & $\mathbf{r}_{\text {eq }}$ & $\Delta \mathbf{E}_{\mathrm{HB}}$ & $\mathbf{r}_{\mathrm{eq}}$ & $\Delta \mathrm{E}_{\mathrm{HB}}$ \\
\hline M06-2X & 3.06 & -2.51 & 3.08 & $-2.04(0.47)^{b}$ & 3.08 & $-2.02(0.49)^{b}$ \\
\hline M11 & 3.08 & -1.99 & 3.10 & $-1.51(0.48)^{b}$ & 3.10 & $-1.50(0.49)^{b}$ \\
\hline$\omega \mathrm{B} 97 \mathrm{X}$ & 3.08 & -2.60 & 3.10 & $-2.14(0.46)^{b}$ & 3.10 & $-2.13(0.47)^{b}$ \\
\hline$\omega \mathrm{B} 97 \mathrm{XD}$ & 3.12 & -2.55 & 3.14 & $-2.14(0.41)^{b}$ & 3.14 & $-2.11(0.43)^{b}$ \\
\hline
\end{tabular}

${ }^{a}$ In parentheses, the increase with respect to the $\mathrm{NCBr} \cdot \mathrm{bz} \Delta \mathrm{E}_{\mathrm{XB}}$ value. ${ }^{\mathrm{b}}$ In parentheses, the increase with respect to the $\mathrm{H}_{2} \mathrm{O} \cdot \mathrm{bz} \Delta \mathrm{E}_{\mathrm{HB}}$ value.

We then computed the binding energy curves corresponding to the perpendicular approach, on the same side of the benzene ring, of either $\mathrm{NCBr}$ to $\mathrm{bz} \cdot \mathrm{H}_{2} \mathrm{O}$ or $\mathrm{H}_{2} \mathrm{O}$ to $\mathrm{bz} \cdot \mathrm{NCBr}$, keeping the dimers fixed in their respective energy minima (see structure (b) in Figures 3 and 4 for the $\mathrm{NCBr} \cdot \mathrm{bz}$ and $\mathrm{H}_{2} \mathrm{O} \cdot \mathrm{bz}$ dimers, respectively). As obtained for the double T-shaped configuration, the minimum energy geometry for both interactions is only slightly perturbed when $\mathrm{NCBr}$ or $\mathrm{H}_{2} \mathrm{O}$ interact with the dimer rather than with 
benzene alone (see Table 2). However, the corresponding interaction energies undergo even larger variations compared with those obtained for the double T-shaped approach: according to M11, M06-2X, $\omega \mathrm{B} 97 \mathrm{X}$, and $\omega \mathrm{B} 97 \mathrm{XD}$ calculations, $\Delta \mathrm{E}_{\mathrm{XB}}$ and $\Delta \mathrm{E}_{\mathrm{HB}}$ values decrease by $27.3,19.7,19.0,17.4 \%$, and $24.1,18.7,17.7,16.1 \%$, respectively (to be compared with the corresponding values, $16.7,14.4,13.6,12.8 \%$ and $19.3,16.0,15.9,14.4 \%$, of the double T-shaped configuration). Also in this case, the destabilization associated with the trimer formation indicates that $\mathrm{XB}$ and $\mathrm{HB}$, perpendicularly approaching benzene from the same side, are not orthogonal interactions. The larger $\Delta \mathrm{E}$ variations obtained for the perpendicular configuration denote an even greater interdependence between the two interactions with respect to that derived for the double T-shaped one.

The larger destabilization obtained for $\mathrm{XB}$ with respect to $\mathrm{HB}$ reflects the abovementioned weaker $\mathrm{NCBr} \cdot \mathrm{bz} X \mathrm{~B}$ with respect to the $\mathrm{H}_{2} \mathrm{O} \cdot \mathrm{bz} \mathrm{HB}$ in such a bent approach. Interestingly, however, calculations on $\mathrm{NCBr} \cdot[\mathrm{bz} \cdot \mathrm{NCBr}]$ halogen-bonded or $\mathrm{H}_{2} \mathrm{O} \cdot\left[\mathrm{bz} \cdot \mathrm{H}_{2} \mathrm{O}\right]$ hydrogen-bonded trimers in perpendicular configuration (see structure (c) in Figures 3 and 4, respectively) provide again larger destabilization for $X B$ with respect to $H B$, similar to what determined for the double T-shaped configuration. $\Delta \mathrm{E}_{\mathrm{XB}}$ and $\Delta \mathrm{E}_{\mathrm{HB}}$ decrease in fact by $37.4,27.4,25.9,23.0 \%$, and 24.6, 19.5, 18.1, 16.9\% according to M11, M06-2X, $\omega$ B97X, and $\omega \mathrm{B} 97 \mathrm{XD}$ calculations, respectively, compared with the values of the dimers. This suggests a strong interdependence between the two perpendicular halogen-bonded interactions with benzene, despite their weakness with respect to the analogues hydrogen-bonded ones.

\section{Materials and Methods}

DFT geometry optimizations were performed by constraining the interacting molecules to the prefixed (T-shaped and double T-shaped; bent by $45^{\circ}$ with respect to the benzene plane and perpendicular) geometries on the basis set superposition error (BSSE)-free potential energy surface. The distance of the $\mathrm{Br}$ or $\mathrm{H}$ atom from the center of the ring was varied from either 1.8 to $6.0 \AA$ (T-shaped approaches) or 3.3 to $4.7 \AA$ (perpendicular approaches with NCBr) or 2.4 to $3.8 \AA$ (perpendicular approaches with $\mathrm{H}_{2} \mathrm{O}$ ) with $0.1 \AA$ step except for the region of minimum energy where the step size was reduced to $0.02 \AA$. Calculations were performed with the range-separated or long-range corrected GGA functional $\omega$ B97X [51], the hybrid meta-GGA functional M06-2X [52], and the range-separated hybrid meta-GGA functional M11 [53]. They were chosen based on their optimal performance to reproduce both interaction energies and geometry of benchmark CCSD(T)/CBS values, according to our previous studies [41,42]. Additional calculations were performed with $\omega$ B97XD [54] to check the effect of explicitly including dispersion corrections into the $\omega$ B97X functional. For these latter calculations, slightly reduced ranges of distances, including the minima, have been explored. In all cases, a large pruned integration grid (99 radial shells and 590 angular points per shell) was used to avoid artifacts associated with numerical integration procedures, as evidenced by previous investigation on the sensitivity of functionals to the size of the integration grid [55]. All calculations were performed with the aug-cc-PVTZ basis set, using the Gaussian 16 Revision A suite of programs [56].

\section{Conclusions}

The interdependence between halogen bonding and hydrogen bonding with a common $\pi$-electron system of benzene has been investigated by DFT calculations, using as donor molecules $\mathrm{NCBr}$ and $\mathrm{H}_{2} \mathrm{O}$, respectively. Four different functionals, selected among the best performing based on previous investigation on the RX $\cdots \pi \mathrm{XB}$, namely M06-2X, M11, $\omega \mathrm{B} 97 \mathrm{X}$, and $\omega \mathrm{B} 97 \mathrm{XD}$, have been used to build up binding energy curves for both dimeric (i.e., $\mathrm{NCBr} \cdot \mathrm{bz}$ and $\mathrm{H}_{2} \mathrm{O} \cdot \mathrm{bz}$ ) and trimeric (i.e., $\mathrm{NCBr} \cdot\left[\mathrm{bz} \cdot \mathrm{H}_{2} \mathrm{O}\right]$ and $\mathrm{H}_{2} \mathrm{O} \cdot[\mathrm{bz} \cdot \mathrm{NCBr}]$ ) units. Two different configurations of the donor molecules with respect to benzene have been explored, i.e., a double T-shaped and a perpendicular one, where $\mathrm{NCBr}$ and $\mathrm{H}_{2} \mathrm{O}$ point towards the center of the ring from either opposite sides or the same side, perpendicularly to each other, respectively. In both cases, comparison between the interaction energies at the equilibrium distances computed for the trimers and the corresponding dimers indi- 
cates, for all the adopted functionals, that the two interactions cannot be considered strictly orthogonal, in particular as far as the perpendicular approach is concerned.

Supplementary Materials: The following are available online, Figures S1-S6 and S10-S15: Plots of binding energy curves, Figure S7: Fully optimized geometries of the $\mathrm{NCBr} \cdot \mathrm{bz}$ and $\mathrm{H}_{2} \mathrm{O} \cdot \mathrm{bz}$ dimers, Figures $\mathrm{S} 8$ and S9: Bent approaches of $\mathrm{NCBr}$ and $\mathrm{H}_{2} \mathrm{O}$ towards the center of benzene ring, Tables S1-S8 and S10-S17: Binding energies values, Table S9: Equilibrium distances and interaction energies for $\mathrm{NCBr} \cdot \mathrm{bz}$ and $\mathrm{H}_{2} \mathrm{O} \cdot \mathrm{bz}$ dimers in the $45^{\circ}$ approaches.

Author Contributions: Conceptualization, A.F., S.P. and M.S.; Methodology, A.F., S.P. and M.S.; Formal analysis, A.F., S.P. and M.S.; Investigation, R.R., G.R. and M.S.; Data curation, A.F., S.P. and M.S.; Writing, A.F., S.P. and M.S.; Supervision, A.F., S.P. and M.S.; Funding acquisition, A.F., S.P. and M.S. All authors have read and agreed to the published version of the manuscript.

Funding: This research received no external funding.

Institutional Review Board Statement: Not applicable.

Informed Consent Statement: Not applicable.

Data Availability Statement: The data presented in this study are available in supplementary materials.

Acknowledgments: The Fondazione Banca del Monte di Lombardia is fully acknowledged for financial support.

Conflicts of Interest: The authors declare no conflict of interest.

Sample Availability: Samples of the compounds are not available from the authors.

\section{References}

1. Desiraju, G.R.; Ho, P.S.; Kloo, L.; Legon, A.C.; Marquardt, R.; Metrangolo, P.; Politzer, P.; Resnati, G.; Rissanen, K. Definition of the halogen bond (IUPAC Recommendations 2013). Pure Appl. Chem. 2013, 85, 1711-1713. [CrossRef]

2. Auffinger, P.; Hays, F.A.; Westhof, E.; Ho, P.S. Halogen bonds in biological molecules. Proc. Natl. Acad. Sci. USA 2004, 101, 16789-16794. [CrossRef]

3. Parker, A.J.; Stewart, J.; Donald, K.J.; Parish, C.A. Halogen bonding in DNA base pairs. J. Am. Chem. Soc. 2012, 134, 5165-5172. [CrossRef]

4. Scholfield, M.R.; Zanden, C.M.V.; Carter, M.; Ho, P.S. Halogen bonding (X-bonding): A biological perspective. Protein Sci. 2013, 22, 139-152. [CrossRef] [PubMed]

5. Wilcken, R.; Zimmermann, M.O.; Lange, A.; Joerger, A.C.; Boeckler, F.M. Principles and applications of halogen bonding in medicinal chemistry and chemical biology. J. Med. Chem. 2013, 56, 1363-1388. [CrossRef] [PubMed]

6. Carter, M.; Voth, A.R.; Scholfield, M.R.; Rummel, B.; Sowers, L.C.; Ho, P.S. Enthalpy-entropy compensation in biomolecular halogen bonds measured in DNA junctions. Biochemistry 2013, 52, 4891-4903. [CrossRef]

7. Ho, P.S. Halogen bonding in medicinal chemistry: From observation to prediction. Future Med. Chem. 2017, 9, 637-640. [CrossRef]

8. Kolár, M.H.; Tabarrini, O. Halogen Bonding in Nucleic Acid Complexes: Miniperspective. J. Med. Chem. 2017, 60, 8681-8690. [CrossRef]

9. Frontera, A.; Bauza, A. Halogen bonds in protein nucleic acid recognition. J. Chem. Theory Comput. 2020, 16, 4744-4752. [CrossRef] [PubMed]

10. Piña, M.D.L.N.; Frontera, A.; Bauza, A. Quantifying intramolecular Halogen Bonds in Nucleic Acids: A combined PDB and theoretical study. ACS Chem. Biol. 2020, 15, 1942-1948. [CrossRef]

11. Nunes, R.S.; Vila-Viçosa, D.; Costa, P.J. Halogen Bonding: An Underestimated Player in Membrane-Ligand Interactions. J. Am. Chem. Soc. 2021, 143, 4253-4267. [CrossRef] [PubMed]

12. Kampes, R.; Zechel, S.; Hager, M.D.; Schubert, U.S. Halogen bonding in polymer science: Towards new smart materials. Chem. Sci. 2021, 12, 9275-9286. [CrossRef]

13. Priimagi, A.; Cavallo, G.; Metrangolo, P.; Resnati, G. The Halogen Bond in the Design of Functional Supramolecular Materials: Recent Advances. Acc. Chem. Res. 2013, 46, 2686-2695. [CrossRef] [PubMed]

14. Virkki, M.; Tuominen, O.; Forni, A.; Saccone, M.; Metrangolo, P.; Resnati, G.; Kauranen, M.; Priimagi, A. Halogen bonding enhances nonlinear optical response in poled supramolecular polymers. J. Mater. Chem. C 2015, 3, 3003-3006. [CrossRef]

15. Yushina, I.D.; Masunov, A.E.; Lopez, D.; Dyakov, A.A.; Bartashevich, E.V. Toward First-Principles Design of Organic Nonlinear Optical Materials: Crystal Structure Prediction and Halogen Bonding Impact on Hyperpolarizabilities of 2-Iodo-3-hydroxypyridine. Cryst. Growth Des. 2018, 18, 5069-5079. [CrossRef]

16. Virkki, M.; Maurice, A.; Forni, A.; Sironi, M.; Dichiarante, V.; Brevet, P.-F.; Metrangolo, P.; Kauranen, M.; Priimagi, A. On molecular optical nonlinearity of halogen-bond-forming azobenzenes. Phys. Chem. Chem. Phys. 2018, 20, 28810-28817. [CrossRef] 
17. McAllister, L.J.; Präsang, C.; Wong, J.P.; Thatcher, R.J.; Whitwood, A.C.; Donnio, B.; O’Brien, P.; Karadakov, P.B.; Bruce, D.W. Halogen-bonded liquid crystals of 4-alkoxystilbazoles with molecular iodine: A very short halogen bond and unusual mesophase stability. Chem. Commun. 2013, 49, 3946-3948. [CrossRef] [PubMed]

18. Vapaavuori, J.; Siiskonen, A.; Dichiarante, V.; Forni, A.; Saccone, M.; Pilati, T.; Pellerin, C.; Shishido, A.; Metrangolo, P.; Priimagi, A. Supramolecular control of liquid crystals by doping with halogen-bonding dyes. RSC Adv. 2017, 7, 40237-40242. [CrossRef]

19. Wang, H.; Bisoyi, H.; Urbas, A.; Bunning, T.; Li, Q. The Halogen Bond: An Emerging Supramolecular Tool in the Design of Functional Mesomorphic Materials. Chem. Eur. J. 2019, 25, 1369-1378. [CrossRef]

20. Clark, T.; Hennemann, M.; Murray, J.S.; Politzer, P. Halogen bonding: The sigma hole. J. Mol. Model. 2007, 13, 291-296. [CrossRef]

21. Franchini, D.; Forni, A.; Genoni, A.; Pieraccini, S.; Gandini, E.; Sironi, M. The Origin of the $\sigma$-Hole in Halogen Atoms: A Valence Bond Perspective. ChemistryOpen 2020, 9, 445-450. [CrossRef]

22. Rendine, S.; Pieraccini, S.; Forni, A.; Sironi, M. Halogen bonding in ligand-receptor systems in the framework of classical force fields. Phys. Chem. Chem. Phys. 2011, 13, 19508-19516. [CrossRef]

23. Ibrahim, M.A.A. Molecular mechanical study of halogen bonding in drug discovery. J. Comput. Chem. 2011, 32, 2564-2574. [CrossRef]

24. Kolár, M.; Hobza, P. On extension of the current biomolecular empirical force field for the description of halogen bonds. J. Chem. Theory Comput. 2012, 8, 1325-1333. [CrossRef] [PubMed]

25. Kolár, M.; Hobza, P.; Bronowska, A.K. Plugging the explicit $\sigma$-holes in molecular docking. Chem. Commun. 2013, 49, 981-983. [CrossRef] [PubMed]

26. Franchini, D.; Dapiaggi, F.; Pieraccini, S.; Forni, A.; Sironi, M. Halogen bonding in the framework of classical force fields: The case of chlorine. Chem. Phys. Lett. 2018, 712, 89-94. [CrossRef]

27. Titov, O.I.; Shulga, D.A.; Palyulin, V.A. Quadrupole Correction: From Molecular Electrostatic Potential to Free Energies of Halogen Bonding. J. Chem. Theory Comput. 2019, 15, 1159-1167. [CrossRef]

28. Otte, F.; Kleinheider, J.; Hiller, W.; Wang, R.; Englert, U.; Strohmann, C. Weak yet Decisive: Molecular Halogen Bond and Competing Weak Interactions of Iodobenzene and Quinuclidine. J. Am. Chem. Soc. 2021, 143, 4133-4137. [CrossRef] [PubMed]

29. Forni, A.; Franchini, D.; Dapiaggi, F.; Pieraccini, S.; Sironi, M.; Scilabra, P.; Pilati, T.; Petko, K.I.; Resnati, G.; Yagupolkii, Y.L. Featuring I $\cdots \mathrm{N}$ Halogen Bond and Weaker Interactions in Iodoperfluoroalkylimidazoles: An Experimental and Theoretical Charge Density Study. Cryst. Growth Des. 2019, 19, 1621-1631. [CrossRef]

30. Wang, R.; Kalf, I.; Englert, U. Insight into trifluoromethylation-Experimental electron density for Togni reagent I. RSC Adv. 2018, 8, 34287-34290. [CrossRef]

31. Wang, R.; Hartnick, D.; Englert, U. Short is strong: Experimental electron density in a very short N …I halogen bond. Z. Kristallogr. Cryst. Mater. 2018, 233, 733-744. [CrossRef]

32. Pavan, M.S.; Jana, A.K.; Natarajan, S.; Guru Row, T.N. Halogen Bonding and Chalcogen Bonding in 4,7-Dibromo-5,6-dinitro-2,1,3benzothiadiazole. J. Phys. Chem. B 2015, 119, 11382-11390. [CrossRef] [PubMed]

33. Pavan, M.S.; Pal, R.; Nagarajan, K.; Guru Row, T.N. Characterization of Interactions Involving Bromine in 2,2-Dibromo-2,3dihydroinden-1-one via Experimental Charge Density Analysis. Cryst. Growth Des. 2014, 14, 5477-5485. [CrossRef]

34. Hathwar, V.R.; Gonnade, R.G.; Munshi, B.; Bhadbhade, M.M.; Guru Row, T.N. Halogen Bonding in 2,5-Dichloro-1,4-benzoquinone: Insights from Experimental and Theoretical Charge Density Analysis. Cryst. Growth Des. 2011, 11, 1855-1862. [CrossRef]

35. Forni, A. Experimental and theoretical study of the $\mathrm{Br} \cdots \mathrm{N}$ halogen bond in complexes of 1,4-dibromotetrafluorobenzene with dipyridyl derivatives. J. Phys. Chem. A 2009, 113, 3403-3412. [CrossRef] [PubMed]

36. Riel, A.M.S.; Rowe, R.K.; Ho, E.N.; Carlsson, A.-C.C.; Rappé, A.K.; Berryman, O.B.; Ho, P.S. Hydrogen Bond Enhanced Halogen Bonds: A Synergistic Interaction in Chemistry and Biochemistry. Acc. Chem. Res. 2019, 52, 2870-2880. [CrossRef]

37. Topić, F.; Rissanen, K. Systematic Construction of Ternary Cocrystals by Orthogonal and Robust Hydrogen and Halogen Bonds. J. Am. Chem. Soc. 2016, 138, 6610-6616. [CrossRef]

38. Lu, Y.; Zhang, S.; Peng, C.; Liu, H. Interplay between Halogen and Hydrogen Bonds in 2D Self-Assembly on the Gold Surface: A First-Principles Investigation. J. Phys. Chem. C 2017, 121, 24707-24720. [CrossRef]

39. van Terwingen, S.; Brüx, D.; Wang, R.; Englert, U. Hydrogen-Bonded and Halogen-Bonded: Orthogonal Interactions for the Chloride Anion of a Pyrazolium Salt. Molecules 2021, 26, 3982. [CrossRef]

40. Voth, A.R.; Khu, P.; Oishi, K.; Ho, P.S. Halogen bonds as orthogonal molecular interactions to hydrogen bonds. Nat. Chem. 2009, 1, 74-79. [CrossRef]

41. Forni, A.; Pieraccini, S.; Rendine, S.; Gabas, F.; Sironi, M. Halogen-Bonding Interactions with $\pi$ Systems: CCSD(T), MP2, and DFT Calculations. ChemPhysChem 2012, 13, 4224-4234. [CrossRef]

42. Forni, A.; Pieraccini, S.; Rendine, S.; Sironi, M. Halogen Bonds with Benzene: An Assessment of DFT Functionals. J. Comput. Chem. 2014, 35, 386-394. [CrossRef]

43. Forni, A.; Pieraccini, S.; Franchini, D.; Sironi, M. Assesment of DFT Functionals for QTAIM Topological Analysis of Halogen Bonds with Benzene. J. Phys. Chem. A 2016, 120, 9071-9080. [CrossRef]

44. Sun, H.; Horatscheck, A.; Martos, V.; Bartetzko, M.; Uhrig, U.; Lentz, D.; Schmieder, P.; Marc Nazaré, M. Direct Experimental Evidence for Halogen-Aryl $\pi$ Interactions in Solution from Molecular Torsion Balances. Angew. Chem. Int. Ed. 2017, 56, 6454-6458. [CrossRef] 
45. Xu, Z.; Yang, Y.; Liu, Y.; Lu, Y.; Chen, K.; Zhu, W. Halogen Bond: Its Role beyond Drug-Target Binding Affinity for Drug Discovery and Development. J. Chem. Inf. Model. 2014, 54, 69-78. [CrossRef]

46. Groom, C.R.; Bruno, I.J.; Lightfoot, M.P.; Ward, S.C. The Cambridge Structural Database. Acta Cryst. 2016, B72, 171-179. [CrossRef]

47. Burns, L.A.; Álvaro Vázquez-Mayagoitia, A.; Sumpter, B.G.; Sherrill, C.D. Density-functional approaches to noncovalent interactions: A comparison of dispersion corrections (DFT-D), exchangehole dipole moment (XDM) theory, and specialized functionals. J. Chem. Phys. 2011, 134, 084107. [CrossRef] [PubMed]

48. Otero-de-la-Roza, A.; Johnson, E.R.; DiLabio, G.A. Halogen Bonding from Dispersion-Corrected Density-Functional Theory: The Role of Delocalization Error. J. Chem. Theory Comput. 2014, 10, 5436-5447. [CrossRef] [PubMed]

49. Shields, Z.P.-I.; Murray, J.S.; Politzer, P. Directional tendencies of halogen and hydrogen bonding. Int. J. Quantum Chem. 2010, 110, 2823-2832. [CrossRef]

50. Liu, F.; Du, L.; Zhang, D.; Gao, J. Performance of Density Functional Theory on the Anisotropic Halogen …Halogen Interactions and Potential Energy Surface: Problems and Possible Solutions. Int. J. Quantum Chem. 2016, 116, 710-717. [CrossRef]

51. Chai, J.D.; Head-Gordon, M. Systematic Optimization of Long-Range Corrected Hybrid Density Functionals. J. Chem. Phys. 2008, 128, 084106. [CrossRef]

52. Zhao, Y.; Truhlar, D.G. The M06 Suite of Density Functionals for Main Group Thermochemistry, Thermochemical Kinetics, Noncovalent Interactions, Excited States, and Transition Elements: Two New Functionals and Systematic Testing of Four M06-Class Functionals and 12 Other Functionals. Theor. Chem. Acc. 2008, 120, 215-241.

53. Peverati, R.; Truhlar, D.G. Improving the Accuracy of Hybrid Meta-GGA Density Functionals by Range Separation. J. Phys. Chem. Lett. 2011, 2, 2810-2817. [CrossRef]

54. Chai, J.-D.; Head-Gordon, M. Long-range corrected hybrid density functionals with damped atom-atom dispersion corrections. Phys. Chem. Chem. Phys. 2008, 10, 6615-6620. [CrossRef] [PubMed]

55. Johnson, E.R.; Wolkow, R.A.; DiLabio, G.A. Application of 25 Density Functionals to Dispersion-Bound Homomolecular Dimers. Chem. Phys. Lett. 2004, 394, 334-338. [CrossRef]

56. Frisch, M.J.; Trucks, G.W.; Schlegel, H.B.; Scuseria, G.E.; Robb, M.A.; Cheeseman, J.R.; Scalmani, G.; Barone, V.; Petersson, G.A.; Nakatsuji, H.; et al. Gaussian 16 Rev. A.03; Gaussian, Inc.: Wallingford, CT, USA, 2016. 